\title{
The Effectiveness of Augmented Reality for English (AR4E) in Vocabulary Learning among Primary 2
}

\section{Pupils}

\author{
Amalina binti Hasbi ${ }^{1} *$ \& Melor Md. Yunus ${ }^{1}$ \\ ${ }^{1}$ Universiti Kebangsaan Malaysia, Malaysia \\ *Corresponding author: Universiti Kebangsaan Malaysia, Malaysia. E-mail: \\ amalinahasbi@gmail.com
}

Received: June 25, 2021 Accepted: July 27, 2021 Published: September 12, 2021

doi:10.5296/ije.v13i3.18808ＵRL: https://doi.org/10.5296/ije.v13i3.18808

\begin{abstract}
This paper presents and discusses a part of an action research conducted to evaluate the effectiveness of Augmented Reality for English (AR4E) in vocabulary learning among Primary 2 pupils as indicated in the results of the pre-test, post-test and observation checklist. An action research was employed. However, this paper reports on the pre-test, post-test and observation checklist conducted in the observation, evaluation and reflection stages only. Purposive sampling was employed as the participants were of the same proficiency level in which it was carried out with 14 below average Primary 2 pupils in SKTEN. Two data collection instruments which were pre-test, post-test and observation checklist were analysed statistically and thematically. The pre-test and post-test were analysed using SPSS Version 25 and it showed a higher mean score in the post-test and this is supported by the findings obtained through the given themes of observation. The results reflected that the implementation of AR4E has shown a significant improvement in learner's vocabulary learning. In addition, the findings have also raised the concern regarding the impact of AR4E in encouraging fun learning, collaborative learning and providing the learners with new language learning experience. Accordingly, the use of AR4E is recommended in vocabulary teaching and learning for English. Finally, the researcher suggests future research can be carried out taking into account differentiated learning tasks in AR4E, larger target users and different language skills to be integrated in AR4E.
\end{abstract}

Keywords: vocabulary learning, augmented reality, English, language learning 


\section{Introduction}

In this global world, being proficient in different languages is undeniably one of the most important factors that can help one to strive forward. A universal language is needed to communicate beyond the border due to globalisation and information revolution in which English has been prioritised. Hence, in Malaysia's context, the stress has also been given on developing pupils' proficiency in English language. This is also stated in the Malaysian Blueprint 2013-2025, “...ensure every child is proficient in Bahasa Malaysia and English language..." (Ministry of Education, 2013, p. 33). In the context of this research, based on the School Based Assessment Report 2019, the pupils' proficiency level selected for this paper are mostly within below average category. Pupils can read and understand simple phrases and sentences with visual support and full guidance and can use simple phrases and sentences in speaking and writing with visual support and full guidance (School Based Assessment Report, 2019). Accordingly, realising such kind of situation, this study was designed.

On that note, to develop pupils' proficiency skills in English language, vocabulary acquisition plays an important role in language learning. Kilic (2019) stated that "vocabulary knowledge is an essential component of linguistic competence..." (p. 134) and this is supported by Schmitt (2019), "learners need large vocabularies to successfully use the second language..." (p. 265). In that sense, it shows that vocabulary acquisition is very useful in building pupils' basic skills in English and assisting them in learning the language skills such as listening, speaking, reading and writing. Nonetheless, vocabulary learning is often seen as a complementary in language learning in which Azizi (2016) revealed that "although the course curriculum was often quite specific about aspects of teaching such as grammar, reading and writing, little specification was given to the role of vocabulary" (p. 773). Thus, vocabulary becomes the focus in this study.

In addition, the use of augmented reality (AR) in vocabulary learning also becomes the focus in this study as it can be an added element in the teaching and learning of English. However, this paper reports on the pre-test, post-test and observation checklist conducted in the observation, evaluation and reflection stages only. After all, classroom activities should be in line with the current needs and the learners' needs (Kirmizi and Komec, 2019). AR was selected in this research as it can provide various interesting visual media that can support instructional strategies compared to using printed flashcards in vocabulary learning. Vasilevski \& Birt (2020) also further explained that teachers should consider that students tend to learn more using virtual media rather than listening or reading. Therefore, in this study, the use of AR-based teaching and learning material named AR4E (Augmented Reality for English) was designed to enhance pupils' vocabulary learning. Apart from that, the findings of this study can be used to reflect that there are various ways in teaching and learning vocabulary especially when in dealing with technology in education. In line with that, the research objective is to evaluate the effectiveness of AR4E in vocabulary learning among Primary 2 pupils. Thus, the research question is: To what extent AR4E could improve vocabulary learning of Primary 2 pupils? 


\section{Literature Review}

\subsection{Vocabulary Learning}

In developing pupils' proficiency in English, vocabulary plays an important role in language learning. Firstly, it is believed that acquiring a large number of vocabularies can lead to a better understanding of the language. Vocabulary can assist the learners in developing themselves better in language skills such as listening, speaking, reading and writing skills. This is in coherent with the statement by Shabaneh \& Farrah (2018), "in order for people to express themselves and be understood by others, both sides (sender-recipient) need to be acquainted with a sufficient amount of vocabulary" (p. 81). As a matter of fact, vocabulary is considered as the core essence that allows the learners to practice the language successfully. At the same time, vocabulary knowledge can be used for various purposes such as to communicate or to seek information.

However, "traditionally, vocabulary was neglected in language teaching programs and curriculums for the sake of grammar and other parts of the language" (Amiryousefi \& Dastjerdi, 2010, p. 89). Vocabulary is only exposed to the learners through language skills. Azizi (2016) said that "although the course curriculum was often quite specific about aspects of teaching such as grammar, reading and writing, little specification was given to the role of vocabulary" (p. 773). In local context, it can be seen that vocabulary is still held as secondary as it is embedded in the syllabus and pupils are basically equipped and exposed to vocabularies through four main language skills namely, listening, speaking, reading and writing as well as grammar. "The words in Year 2 wordlist are found in the textbook units and in further lessons described within the Scheme of Work" (Ministry of Education, 2015, p. 2). Hence, in this study, vocabulary learning was prioritised as it can greatly influence pupils' proficiency skills.

\subsection{The Use of Augmented Reality in Language Learning}

Shabaneh \& Farrah (2018) stated that "it is of importance to emerge novel teaching style and to focus on student-centered teaching methods, which would result in graduating students who are able to comprehend the language and to communicate efficiently" (p. 79). Thus, in concern with this study, the use of technology in language learning has been taken into consideration. Recently, there are many studies which revealed the positive results of using AR in vocabulary learning._The results show that AR could significantly improve the vocabulary learning (Solak \& Cakir, 2016; Chen \& Chan, 2019; Lee et al., 2019; Yaacob et.al. 2019; Sadikin \& Martyani, 2020; Tsai, 2020). This is also supported by Cheng (2020) in which "AR has a significant effect on students' English vocabulary learning with various levels of low, intermediate and high groups" (p. 170). However, the researches done was generally for language learning purpose and they were not tailored with the latest English curriculum in the local context. With that reason, AR was selected in designing the teaching and learning material known as AR4E which can cater to needs of Primary 2 pupils in line with the latest English curriculum in Malaysia. In spite of that, this study did not explore the effect of using AR on pupils' different learning styles. Hence, the researcher has suggested this aspect to be explored for further research. 


\subsection{Augmented Reality for English (AR4E)}

According to Jamrus \& Razali (2019), "augmented reality takes computer-generated information or digital information such as sound graphics and haptic awareness and superimposing them in real environment" (p. 727). AR brings the users into a virtual reality with various features such as visual graphics, sounds or virtual objects. In this research, an application named Metaverse was used. The contents were developed using Metaverse Studio in the website and various features were employed such as 360-degree pictures, songs, videos, interactive flashcards, games and quizzes. The contents were developed and aligned to the contents in the CEFR textbook; Unit 6: The old house and Unit 7: Get Dressed. Thus, it was named as AR4E (Augmented Reality for English). Once Metaverse application was downloaded in the mobile phone, the participants were required to scan the code provided.

\section{Methods}

\subsection{Research Design}

Based on the research objective, the study employed Lewin (1946) and Laidlaw (1992) action research model. By referring to the cyclical model of Lewin and Laidlaw's model, it consists of five stages; namely identifying the problem, planning, implementing, observing, and reflecting and evaluating. However, this paper only reports on the pre-test, post-test and observation checklist conducted in the observation, evaluation and reflection stages.

\subsection{Research Instrument}

As this study only reports on two stages namely, observation, evaluation and reflection stages, the instruments employed were the pre-test, post-test and observation checklist. The pre-test and post-test were employed to evaluate the effectiveness of using AR4E in vocabulary learning as Ary et.al (2010) stated that "a test is a set of stimuli presented to an individual to elicit responses on the basis of which numerical score can be assigned" (p. 201). Before the implementation of AR4E in vocabulary learning, pre- test was administered. The purpose of pre- test was to collect and analyse pupils' prior knowledge of vocabulary for the selected unit in the textbook. Post- test was administered to collect the data after the implementation of AR4E in vocabulary learning.

In both pre- test and post- test, the vocabulary introduced and used were taken from the same topic based on the textbook; Unit 6: The Old House and Unit 7: Get Dressed as shown in Table 3.1 and Table 3.2. Hence, there is a connection between what the pupils are supposed to learn and the test they are required to take. Although both pre- test and post- test contain the same vocabulary items, the way the questions were constructed in both tests are different. This ensures that the pupils were tested on their vocabulary knowledge, instead of the technicality affecting the result of the test. 
Table 1. List of Vocabulary to be Used in Unit 6

\begin{tabular}{cc}
\hline & List of vocabulary/ Word list \\
\hline 1 & living room \\
2 & dining room \\
3 & bedroom \\
4 & bathroom \\
5 & kitchen \\
6 & cellar \\
7 & stairs \\
8 & hall \\
\hline
\end{tabular}

Table 2. List of Vocabulary to be Used in Unit 7

\begin{tabular}{lc}
\hline & List of vocabulary/ Word list \\
\hline 1 & shoes \\
2 & t-shirt \\
3 & skirt \\
4 & sweater \\
5 & jacket \\
6 & jeans \\
7 & short \\
8 & socks \\
\hline
\end{tabular}

In this study, a critical observation was also carried out as it was employed in the observing stage. A previously developed instrument was used in this research as the indicators in the selected instrument can represent the attainment needed in this research. The questions stated in the critical observation were adapted from Evaluative Criteria of an English Language Textbook Evaluation Criteria by Mukundan \& Nimehchisalem (2012). The five evaluative criteria include general attribute, suitability to learners, physical and utilitarian attributes, learning and teaching content, vocabulary and pronunciation. The critical observation was given to the teacher who was invited to monitor and observe the implementation of the research. By providing them with the critical observations, it helped them to narrow down their observations.

\subsection{Research Participants}

As this study aims to improve the vocabulary learning among Primary 2 pupils, the researcher had been actively involved to monitor and instruct the pupils throughout the action research. Due to the nature of this study and the research design, purposive sampling was selected. Firstly, as there is one Primary 2 class in SKTEN, Nyabor, Sarawak, all 14 pupils were involved in this research. The selected participants are also below average learners based on the data recorded in their School Based Assessment in 2019. In the context of this 
study, average learners were chosen as the data gained from these learners would be able to evaluate the effectiveness of AR4E. Based on the report, pupils can read and understand simple phrases and sentences with visual support and full guidance and can use simple phrases and sentences in speaking and writing with visual support and full guidance (School Based Assessment Report 2019). At the same time, as the researcher was also teaching this class, it provided easy accessibility and availability at a given time for the researcher to carry out the study. Hence, Primary 2 was also selected as the participants in this study.

\subsection{Research Analysis}

\subsubsection{Pre-test and Post-test}

The total questions in pre- test are 20 questions and post-test also comprise of 20 questions. After administering both pre- test and post- test, the number of correct questions were divided by total number of questions in each test. It was then be multiplied by $100 \%$ to get the percentage of the pupil's score.

Once the pre- test and post- test were calculated, their scores were placed with reference to the Criterion Referenced Assessment (CRA) in reference to KSSR syllabus. The CRA based on the KSSR syllabus is applied to analyse the vocabulary assessment of Primary Year 2 pupils in the pre- test and post- test. In this research, the assessment was not based on CEFR as it is summative-based. Based on Table 3.3, pupils who scored between 80 to 100 were categorised as excellent, meanwhile those who scored between 65 to 79 were considered as good. Pupils who achieved 50 to 64 is at the satisfactory level and 40 to 49 is at minimum level. Lastly, those with the score between $0-39$ were categorised as still below minimum level.

Table 3. Criterion Referenced Assessment (CPA) in Reference to KSSR Syllabus

\begin{tabular}{ccc}
\hline Range of scores & Grade & Remarks \\
\hline $80-100$ & $\mathrm{~A}$ & Excellent \\
$65-79$ & $\mathrm{~B}$ & Good \\
$50-64$ & $\mathrm{C}$ & Satisfactory \\
$40-49$ & $\mathrm{D}$ & Achieve minimum level (adequate) \\
$0-39$ & $\mathrm{E}$ & Below minimum level (poor) \\
\hline
\end{tabular}

Source: Sistem Analisis Peperiksaan Sekolah (2016)

The data from both pre- test and post- test were analysed using SPSS Version 25 where the percentage from pre- test and post- test were calculated. This is to compare the learners' results before and after the implementation of AR4E in vocabulary learning. At the same time, the differences in result of pre-test and post-test were also analysed and recorded. 


\subsubsection{Critical Observation}

Thematic analysis was used to analyse the data collected through critical observation and it is "...the process of identifying patterns or themes within qualitative data" (Maguire \& Delahunt, 2017, p. 3352). The data was analysed by categorising specific keywords and patterns in the critical observation. In the context of this research, the keywords or specific criteria include 1) general attribute, 2) suitability to learners, 3) physicality and utilitarian attributes, 4) learning and teaching content, 5) vocabulary and 6) pronunciation. Based on the specific criteria stated, the patterns of words were analysed.

\subsection{Validity and Reliability of Pre-test and Post-test and Observation Checklist}

\subsubsection{Face and Content Validity of Pre-test and Post-test}

Face validity of this pre- test and post- test was obtained when the researcher sought for the expert teacher to analyse the items in both tests given to the research participants. On that note, her expertise and teaching experiences can be used to obtain the content validity of both tests. Based on her suggestions and feedbacks, the pre- test and post- test suited the level of pupils' age and interest. Apart from that, considering the level of the pupils, the test was suitable to be used to assess their vocabulary learning before and after the use of AR4E in vocabulary learning. This is also in line with the Piaget's theory of cognitive development as both tests do provide the pictures to supplement pupils' comprehension of the vocabulary presented in the tests. At the same time, the tests were not wordy as pupils' anxiety will be increased if the tests were too complicated and wordy.

Besides that, content validity is also concerned to ensure that both pre- test and post- test can measure the learning items which pupils are supposed to be introduced to. The item in both tests contained all the vocabulary listed in Year 2 Syllabus. Furthermore, the scores from the tests were graded by using Criterion Referenced Assessment (CRA) for KSSR. Therefore, this method is agreed by Ary et.al (2010), it is stated that content validity is achieved when an instrument has appropriate content for measuring a complex concept, or construct.

\subsubsection{Face and Content Validity of Observation Checklist}

As the observation checklist was adapted from Evaluative Criteria of an English Language Textbook Evaluation Criteria by Mukundan \& Nimehchisalem (2012), it did ascertain the face and content of validity of this research. All the statements in the observational checklist were constructed based on the research objectives; to evaluate the effectiveness of vocabulary learning before and after the use of AR4E.

\section{Findings}

\subsection{Pre-test and Post-test}

After the implementation of AR4E, the post-test was administered to evaluate the effectiveness of using AR4E in vocabulary learning. At this stage, the post-tests were also checked and reviewed by the researcher with the assistance of the expert teacher. To obtain 
the mean score and percentages, the post-tests' results were tabulated in the SPSS Version 25. Both scores from pre-test and post-test were compared to see the differences in vocabulary learning before and after the implementation of AR4E. Table below shows the percentages, mean scores and the differences of pre-tests' and post-tests' results.

Table 4. Percentages, Mean Score and Differences of Pre- and Post-Test Results Unit 6

\begin{tabular}{|c|c|c|c|c|c|}
\hline \multirow[t]{2}{*}{ Pseudonym } & \multicolumn{4}{|c|}{ Result (\%) } & \multirow{2}{*}{$\begin{array}{l}\text { Differences of } \\
\text { results }(\%)\end{array}$} \\
\hline & $\begin{array}{l}\text { Pre- } \\
\text { test }\end{array}$ & Grade & $\begin{array}{l}\text { Post- } \\
\text { test }\end{array}$ & Grade & \\
\hline Jacky & 40 & $\mathrm{D}$ & 45 & $\mathrm{D}$ & +5 \\
\hline Damia & 45 & $\mathrm{D}$ & 60 & $\mathrm{C}$ & +15 \\
\hline Syifar & 45 & $\mathrm{D}$ & 55 & $\mathrm{C}$ & +10 \\
\hline Anis & 40 & $\mathrm{D}$ & 50 & $\mathrm{C}$ & +10 \\
\hline Batrisya & 40 & $\mathrm{D}$ & 50 & $\mathrm{C}$ & +10 \\
\hline Amirul & 45 & $\mathrm{D}$ & 55 & $\mathrm{C}$ & +10 \\
\hline Aqil & 65 & B & 90 & $\mathrm{~A}$ & +25 \\
\hline Salsabilla & 60 & $\mathrm{C}$ & 100 & A & +40 \\
\hline Hakim & 70 & $\mathrm{~B}$ & 95 & $\mathrm{~A}$ & +25 \\
\hline Yana & 75 & B & 100 & $\mathrm{~A}$ & +25 \\
\hline Iman & 70 & B & 100 & A & +30 \\
\hline Anaqi & 70 & $\mathrm{~B}$ & 95 & A & +25 \\
\hline Kasyifah & 75 & B & 100 & $\mathrm{~A}$ & +25 \\
\hline Audrie & 65 & $\mathrm{~B}$ & 100 & A & +35 \\
\hline Total & 57.50 & $\mathrm{C}$ & 78.21 & B & +20.71 \\
\hline
\end{tabular}

Based on the results of the post-test, five out of 14 pupils had a score of ranging from $50 \%$ to $60 \%$ which is equivalent to Grade C (Satisfactory), meanwhile eight pupils obtained Grade A (Excellent), ranging from $90 \%$ to $100 \%$. As shown in Table 4.1, Salsabilla has shown the highest improvement in her results which is $40 \%$ in difference of results. The mean score of the total post-test has also improved from $57.50 \%$ to $78.21 \%$ indicating an improvement of $20.71 \%$. This significant improvement shows that pupils' comprehension has been influenced by the implementation of AR4E on the expense of the traditional method in the way the learners showed better comprehension and scores better result in the post-test. Apart from that, the nature of AR4E has also supported learner autonomy in learning. "Autonomous learning is said to make learning more personal and focused and, consequently, is said to achieve better learning outcomes, since learning is based on learners' needs and preferences" (Richards, n.d.). Thus, the improvement in the results showed that AR4E does improve the vocabulary learning among Primary 2 pupils. This is also in coherent with the observational checklist in which "The interactive features helped the learners to distinguish each word better." 
Table 5. Percentages, Mean Score and Differences of Pre- and Post-Test Results Unit 7

\begin{tabular}{cccccc}
\hline \multirow{2}{*}{ Pseudonym } & \multicolumn{4}{c}{ Result (\%) } & $\begin{array}{c}\text { Differences of } \\
\text { results (\%) }\end{array}$ \\
\cline { 2 - 5 } & Pre-test & Grade & Post-test & Grade & +10 \\
\hline Jacky & 40 & $\mathrm{D}$ & 50 & $\mathrm{C}$ & +5 \\
Damia & 40 & $\mathrm{D}$ & 45 & $\mathrm{D}$ & +5 \\
Syifar & 40 & $\mathrm{D}$ & 45 & $\mathrm{D}$ & +10 \\
Anis & 45 & $\mathrm{D}$ & 55 & $\mathrm{C}$ & +15 \\
Batrisya & 40 & $\mathrm{D}$ & 55 & $\mathrm{C}$ & +20 \\
Amirul & 40 & $\mathrm{D}$ & 60 & $\mathrm{C}$ & +20 \\
Aqil & 70 & $\mathrm{~B}$ & 90 & $\mathrm{~A}$ & +35 \\
Salsabilla & 60 & $\mathrm{C}$ & 95 & $\mathrm{~A}$ & +25 \\
Hakim & 70 & $\mathrm{~B}$ & 95 & $\mathrm{~A}$ & +20 \\
Yana & 75 & $\mathrm{~B}$ & 95 & $\mathrm{~A}$ & +20 \\
Iman & 80 & $\mathrm{~A}$ & 100 & $\mathrm{~A}$ & +10 \\
Anaqi & 80 & $\mathrm{~A}$ & 90 & $\mathrm{~A}$ & +20 \\
Kasyifah & 75 & $\mathrm{~B}$ & 95 & $\mathrm{~A}$ & +30 \\
Audrie & 70 & $\mathrm{~B}$ & 100 & $\mathrm{~A}$ & +17.5 \\
Total & 58.93 & $\mathrm{C}$ & 76.43 & $\mathrm{~B}$ & \\
\hline
\end{tabular}

Meanwhile, for Unit 7, from the results of the post-test, four out of 14 pupils scored a satisfactory result ranging from $50 \%$ to $60 \%$ which is equivalent to Grade $\mathrm{C}$ (Satisfactory). Besides that, the mean score of the total post-test was $76.43 \%$, implying that overall, the participants had achieved a "Good" (Grade B) result. The research participants also showed that they have improved in an average of $17.5 \%$. This is also in line with the observation recorded by the expert teacher in which it is stated that, "The learners were not pressured with too many words; hence they could pick up the words." It was also noted by the researcher as "...they were able to answer the quizzes correctly." Therefore, the increased percentage of post-test result showed that the use of AR4E enhanced the learning of vocabulary.

\subsection{Observation Checklist}

The observation was carried out within the four periods of English lesson with the expert teacher so that the validity and authenticity of the data obtained was assured. The observations involved six elements namely; (1) general attribute, (2) suitability to learners, (3) physical and utilitarian attributes, (4) learning and teaching content, (5) vocabulary and (6) pronunciation. Once the data were collected, the observation checklist of both the researcher and the expert teachers were triangulated to identify the similarities and differences of the observations based on the elements to evaluate the participants' comprehension on the learning of vocabulary using AR4E. The data triangulated from the observational checklist based on the adaptation and adoption from Evaluative Criteria of an English Language Textbook Criteria by Mukudan \& Nimehchisalem (2012) is presented in Table below to ascertain the participants' learning achievement of vocabulary. 
Based on the six elements in the observation checklist, both the researcher and expert teacher came out with consistent remarks. In the first element, they were to observe the general attribute of AR4E. It shows that both remarks are congruous as AR4E is "in line with the current English syllabus." It was also noted that the expert teacher stated that AR4E can be used for pupils' revision. However, this matter will be discussed further in the recommendations and suggestions.

Next, in the second element, it focuses on the suitability to learners. The suitability to learners is evaluated in terms of age, needs and interests of learners. AR4E was described as suitable to the age of learners as it can be seen that they "enjoyed the learning session." According to Babakr et .al (2019), "Piaget suggested that children during this period are less egocentric; they display the ability to understand concert things and they can solve problems" (p. 519) This means that AR4E does support this statement as they were seen "smiling" and "enjoyed the learning session." At the same time, it is also stated by both the researcher and the expert teacher that this innovation does cater to the needs of learners as the learners were not pressured to learn too many vocabs at once. Thus, it is easier for them to pick up the words they were exposed to. At the same time, it is also observed that AR4E is suitable to the interests of the learners as they "excitedly clicked and explored the application to see what will pop up next." All in all, AR4E is suitable for the learners considering their age, needs and interests.

For the third element, the focus is geared towards physical and utilitarian attributes of AR4E. There are different aspects observed such as the layout, the use of text and visual, the cost and the convenience aspect. Both the researcher and the expect teacher agreed that AR4E does fit all the aspects stated in the observation checklist. AR4E has an attractive layout as "pupils can easily understand what to click and be familiar with the app in a short time" and "pupils loved chasing after the animation and laughed at the funny animation." AR4E is also convenient for the learners to use as it was observed that they did not have any problem in handling and using the app. "Authentic, engaging tasks with real-world connections motivate student effort and engagement which is supporter through teacher scaffolding and a wide range of tools that allows for personalised learning and student agency" (Hammond, 2020, p. 101). In a nutshell, AR4E has an interesting layout and suitable use of text and visual which can engage the participants in learning.

In the fourth element, it deals with the learning and teaching content. In regards to vocabulary learning, AR4E is "interesting," the tasks provided are "doable," provides "achievable objectives" and "useful." "It gives them a chance to see the real-world language using authentic material and it is provided for teachers to make a more interactive class by using, for example, online English exercises" (Hermagustiana \& Rusmawaty, 2017, p. 137). At the same time, this innovation also supports "collaborative learning." "Collaborative learning is an effective approach to implement in educational settings owing to its advantages to enhance social interaction, student-centeredness and learner autonomy" (Salma, 2020, p. 4). On that note, during the implementation of AR4E, the participants were observed to communicate with their peers, especially when they were solving the quizzes and looking for the animation. AR4E was also considered as a useful tool in learning as it enhances the participants' 
language use. Alqahtani (2015) as cited in Nation (2001) stated that vocabulary knowledge and language use complement each other; vocabulary knowledge allows language use, and likewise, language use contributes to an improvement in vocabulary knowledge.

For the observation in the fifth element, "vocabulary," AR4E does provide "suitable number of vocabularies" to be introduced to the learners and "repetitive words" throughout the materials assist them in learning better. It increases exposure frequency of learning the English words as each time repetitions of each word occurs. This is in coherent with the result in a study conducted by Mohamed (2018) in which "total times spent on each encounter was positively associated with learning success in all vocabulary measures" ( $p$. 269). On that note, during the implementation of AR4E, it was observed that pupils encountered the words repetitively, such as in the interactive flashcards, while listening to songs, playing the games and answering the quizzes. Hence, these encounters assist them in learning comprehension and support form recognition.

Lastly, in the sixth element, the pronunciation in AR4E was observed. The pronunciation is "clear," "accurate" and the learners did not face any problem in comprehending the instructions given. This aspect should not be neglected as it also influences the implementation of AR4E. If the pronunciation is unclear and inaccurate, it may affect their understanding and the input received from the materials used. Unclear pronunciation may also influence pupils' interests in learning. Nonetheless, AR4E has successfully cater to this need.

Due to the clear and accurate pronunciation, less guidance was given and they played independently in a fun environment. Therefore, this element is in line with Nurdin Noni (2016) in which he stated that "students should be the primary consideration to be understood by a teacher of English" (p. 228). As AR4E was implemented to improve Primary 2 pupils' vocabulary learning, thus it is of importance that pupils use English learning material which can cater to their needs.

\section{Discussion}

Based on the data collected in the two stages, the use of AR4E does improve pupils' achievement in vocabulary learning. The difference of results between pre-test and post-test in both Unit 6 and Unit 7 has shown a significant improvement. The mean score for Unit 6 has improved from $57.50 \%$ to $78.21 \%$ meanwhile, for Unit 7 , the mean scores rose from $58.93 \%$ to $76.43 \%$, implying that overall, the learners had achieved a "Good" (Grade B) result. This is further supported by the data triangulated in the observational checklist, in which pupils "are able to answer the quizzes provided in AR4E." The triangulated data from observational checklist further proved that the factors such as teaching and learning content, physical and utilitarian attributes and suitability to learners do contribute to the positive outcomes. Additionally, all these factors are in coherent with Piaget's theory of cognitive development. Babakr et.al (2019) stated that, "Piaget suggested that children during this period are less egocentric; they display the ability to understand concert things" (p.519) As 
AR4E combined various media in one teaching and learning material, the learners are able to construct their vocabulary knowledge better according to their age and cognitive development.

The implementation of AR4E also revealed that the learners encountered a new language learning experience. The remarks noted in the observational checklist "They excitedly clicked to see what will pop up next" and "Pupils really loved the 360-degree picture. They moved around and eagerly moved the mobile phone to look at the full picture." This shows that AR4E has successfully coped with the latest trend in education in which technology is encouraged to be integrated in teaching and learning as "the computer-based skills that the digital natives possess today influenced the skills and interests in education in a very significant way" (Mat-jizat et. al, 2017, p. 226). For an instance, unlike using printed flashcards, the learners can learn the English words interactively by clicking on the animation and listen to the pronunciation. Hence, AR4E can serve as a new platform for both educators and learners to learn the language in a novel way and it does suit the needs of learners in this modern era.

The use of AR4E in vocabulary learning has also created a fun and purposeful learning. Pupils "...laughed at the funny animation in AR4E" in the observation checklist. Noted as "interesting and colourful." This is also parallel with the results of the post-test in Unit 6 and Unit 7, which showed a significant improvement and it can be seen in the mean scores (Unit 6: 78.21 and Unit 7: 76.43). The element of fun is essential in language learning to attract the learners' attention as well as to sustain their interest throughout the learning process. Not only that, fun element can also boost their motivation in learning as it reduces their anxiety in learning the second language and thus, it indirectly influenced the learning environment too. When a conducive environment is promoted, it will hinder the learners from creating a mental block in acquiring the vocabulary learnt. In other words, when a 'rise' in the affective filter occurs due to low motivation, weak self-esteem and anxiety, a 'mental block will be formed which will hinder the comprehensible input in language acquisition ( $\mathrm{Li}$ Lin 2019).

Lastly, it is also revealed that AR4E encouraged active and collaborative learning. During the implementation of AR4E, the learners were assigned in pairs to carry it out. It allowed them to interact and cooperate with each other especially in answering the quizzes. Therefore, it supported the statement by Salma (2020) that "collaborative learning is an effective approach to implement in educational settings owing to its advantages to enhance social interaction, student-centeredness and learner autonomy" (p. 4) Furthermore, it was also noted in the observational checklist in which both the expert teacher and researcher stated that "...less guidance was given by the teacher" and "...were able to complete all the tasks in pairs." Consequently, by promoting collaborative learning through AR4E, the teacher has given the learner's autonomy in learning and encourage them to be responsible in learning.

Therefore, based on the data obtained and analysed in the cyclical process, it clearly showed that the use of augmented reality in vocabulary learning had resulted in a positive outcome. AR4E does not only improve vocabulary learning among Primary 2 pupils, pupils also encountered new language learning experience. In addition, AR4E has also successfully 
encouraged a fun and purposeful learning as well as promoting active and collaborative learning.

\section{Conclusions}

Based on the findings, it is reflected that vocabulary learning among Primary 2 pupils can be improved using Augmented Reality for English (AR4E). From the results shown in this research, AR4E was able to assist them in learning the words as it can be seen that the learners' achievement increased after the implementation of AR4E. Apart from that, AR4E also encouraged fun and meaningful learning as AR4E has different interesting features which can attract their attention and arouse their curiosity in learning. Besides that, AR4E has also successfully promoted collaborative learning. In addition, AR4E also exposed the learners to new language learning experience by incorporating language learning and augmented reality. In short, future study is still needed to explore more potential of using augmented reality (AR) in the teaching and learning of English so that more learners can benefit from the use of AR4E in language learning. Few aspects should be taken into consideration in prior to explore the use of AR4E in future study such as taking into account differentiated learning tasks, larger target users and development of other language skills.

\section{Suggestions}

\subsection{Differentiated Learning Tasks}

It was noticed in the observational checklist pertaining the teaching and learning content, that "some of them needed teacher's guidance, especially the beginners" and "...can add more task for advanced learners." Hence, this shows that during the implementation of AR4E, the beginners might have encountered some difficulties and needed guidance from the teacher meanwhile, some of the tasks provided in AR4E might be too easy and not challenging for the advanced learners. This shows that different learning style was not studied in this study. In that respect, it is important to take differentiated learning tasks into consideration in developing the content of AR4E as pointed out by Bondie et. al (2019) that differentiated learning tasks ".... embraced all teacher efforts to meet the perceived needs of students" ( $\mathrm{p}$. 345) This is because one classroom can consist pupils of different English language proficiency levels, so the teacher should take that into consideration in order to cater to their different learning needs. In the next cycle or in the future research, an option which allows the learners to choose the tasks according to their proficiency level can be made available so that it can cater to their learning needs and this will be beneficial for other learners in the long run too.

\subsection{Larger Target Users}

Given the location and background of the school, this study had a limited target user as it solely involved 14 Primary pupils of SKTEN. At the same time, the limited number of learners involved in the study was also related to purposive sampling which provides easy 
accessibility for the researcher. However, due to the positive results and impacts of AR4E in this study, AR4E can be implemented to larger target users. Notably, AR4E has a potential to be administered to more participants. In the meantime, some considerations should be made in prior to administering AR4E with more participants so that it can meet the aims and purposes, for instances the availability of instruments such as pre-test and post-test or the instructions in prior to implementing AR4E in teaching and learning. Some considerations will allow AR4E to be used more effectively and the availability of access to application can be improved too.

\subsection{Development of Other Language Skills}

In this cycle, AR4E is mostly focused on listening and reading skills depending on the features in AR4E. Accordingly, it can still be developed by integrating more language skills such as speaking and writing skills. For an instance, if speaking skills are to be included in AR4E, it will provide a platform for the learners to practice speaking using augmented reality. Thus, it serves a new learning experience for them. This versatility integrated in AR4E can also give impacts towards the learners' learning motivation and interests in addition to developing their English language proficiency levels.

\section{References}

Alqahtani, M. (2015). The Importance of Vocabulary in Language Learning and How to be Taught. International Journal of Teaching and Education, 3(3), 21-34. https://10.20472/TE.2015.3.3.002

Amiryousefi, M., \& Dastjerdi, H. (2010). Vocabulary: Challenges and Debates. English Language Teaching, 3(3), 89-94. http://dx.doi.org/10.5539/elt.v3n3p89

Ary, D., Jacobs, L. C., Sorensen, C., \& Razavieh, A. (2010). Introduction to Research in Education (8th ed.). Wadsworth, USA: Cengage Learning.

Azizi, A. (2016). Effects of non-negotiated pre-modified input, negotiation of input without output, and negotiation of input pushed output on EFL learners' vocabulary learning. Journal of Language Teaching and Research, 7(4), 773-779. http://dx.doi.org/10.17507/jltr.0704.19

Babakr, Z. H., Mohamedamin, P., \& Kakamad, K. (2019). Piaget's Cognitive Developmental Theory: Critical Review. The Asian Institute of Research, 2(3), 517-524. http://doi.org/10.31014/aior.1993.02.03.84

Bondie, R. S., Dahnke, C., \& Zusho, A. (2019). How Does Changing “One-Size-Fits All” to Differentiated Instruction Affect Teaching? Review of Research in Education. 43(1), 336-362. https://doi.org/10.3102/0091732X18821130

Chen, R. W., \& Chan, K. K. (2019). Using Augmented Reality Flashcards to Learn Vocabulary in Early Childhood Education. Journal of Educational Computing, O(0), 1-20. http://dx.doi.org/10.1177/0735633119854028 
Hermagustiana, I., \& Rusmawaty, D. (2017). The Use of Technology for Vocabulary Instruction in EFL Classrooms: Support and Challenges. Advances in Intelligent Systems Research, 144, 137-143. https://doi.org/10.2991/icedutech-17.2018.27

Kiliç, M. (2019). Vocabulary Knowledge as a Predictor of Performance in Writing and Speaking: A Case of Turkish EFL Learners. PASAA, 57, 133-164.

Kırmızı, Ö., \& Kömeç, F. (2019). The Impact of Flipped Classroom on Receptive and Productive Vocabulary Learning. Journal of Language and Linguistic Studies, 15(2), 437-449.

Jamrus, M. H. M., \& Razali, A. B. (2019). Augmented Reality in Teaching and Learning English Reading: Realities, Possibilities and Limitations. International Journal of Academic Research in Progressive Education and Development, 8(4), 724-737. http://dx.doi.org/10.6007/IJARPED/v8-i4/6696

Lee, L. K., Chau, C. H., Chau, C. H., Ng, C. T., Hu, J. H., Wong, C. Y., \& Wu, N. I. (2019). Improving the experience of teaching and learning kindergarten-level English vocabulary using augmented reality. International Journal of Innovation and Learning, 25(2), 110. http://dx.doi.org/10.1504/ijil.2019.097661

Li, L. (2019). Study on The Influence of Affective Factors on Error Correction in Chinese EFL Teaching. $2^{\text {nd }}$ International Conference on Contemporary Education, Social Sciences and Ecological Studies, 109-111. https://doi.org/10.2991/cesses-19.2019.26

Linda, D-H., Lisa, F., Channa, C-H., Brigid, B. \& David, O. (2020). Implications for educational practice of the science of learning and development. Applied Developmental Science, 24(2), 97-140. https://doi.org/10.1080/10888691.2018.1537791

Maguire, M., \& Delahunt, B. (2017). Doing a thematic analysis: A practical, step-by-step guide for learning and teaching scholars. All Ireland Journal of Higher Education, 9(3), 3351-33514.

Mat-jizat, J. E., Jaafar, J., \& Yahaya, R. (2017). Measuring the Effectiveness of Augmented Reality as a Pedagogical Reality Strategy in Enhancing Student Learning and Motivation. International Journal of Academic Research in Business and Social Sciences, 7(1), 225-240. http://dx.doi.org/10.6007/IJARBSS/v7-i1/2601

Ministry of Education. (2013). Malaysia Education Blueprint 2013-2025.

Ministry of Education. (2015). Year 2 Syllabus.

Mohamed, A. A. (2018). Exposure Frequency in L2 Reading. Studies in Second Language Acquisition, 40(2018), 269-293. http://dx.doi.org/10.1017/S0272263117000092

Mukundan, J., \& Nimehchisalem, V. (2012). Evaluative Criteria of an English Language Textbook Evaluation Checklist. Journal of Language Teaching and Research, 3(6), 1128-1134. http://dx.doi.org/10.4304/jltr.3.6.1128-1134

Nihat, S. (2020). Collaborative Learning: An Effective Approach to Promote Language 
Development. International Journal of Social Sciences \& Educational Studies, 7(2), 57-61. http://dx.doi.org/10.23918/ijsses.v7i2p57

Nurdin, N. (2016). Primary School Teachers' Perceptions of and Practices in the Selection and Development of English Learning Materials. International Journal of Linguistics, Literature and Their Teaching, 15(2), 227-238.

Richards, J. C. (n.d.). Autonomous Learner. Retrieved from https://www.professorjackrichards.com/autonomous-learner/

Sadikin, I. S. \& Martyani, E. (2020). Integrating Augmented Reality (AR) in EFL Class for Teaching Vocabulary. Professional Journal of English Education, 3(2), 160-167. http://dx.doi.org/10.22460/project.v3i2.p161-167

School Based Assessment Report. (2019). School Based Assessment Report. Nyabor, Sarawak.

Schmitt, N. (2019). Understanding vocabulary acquisition, instruction, and assessment: A research agenda. Language Teaching, 52(02), 261-274. https://doi.org/10.1017/S0261444819000053

Shabaneh, Y., \& Farrah, M. (2019). The Effect of Games on Vocabulary Retention. Indonesian Journal of Learning and Instruction, 2(1), 79-90. http://dx.doi.org/10.25134/ijli.v2i01.1687

Solak, E., \& Cakir, R. (2015). Exploring the Effect of Materials with Augmented Reality on Language Learner's Vocabulary Learning, 13(2), 50-72. http://dx.doi.org/10.9743/JEO.2015.2.5

Tsai, C-C. (2020). An Action Research Study Exploring the Effects of Augmented Reality for English Vocabulary Learning in an Elementary School in Taiwan. The New Educational Review, 59(1), 163-174. http://dx.doi.org/10.15804/tner.2020.59.1.13

Yaacob, A., Zaludin, F., Aziz, N., Ahmad, N., Othman, N. A., Muhamad, F., \& Rabiatul, A. (2019). Augmented, R. (AR) Flashcards as a Tool to Improve Low Ability Students' Vocabulary. Practitioner Research, 1, 29-52.

Vasilevski, N., \& Birt, J. (2020). Analysing construction Student Experiences of Mobile Mixed Reality Enhanced Learning in Virtual and Augmented Reality Environments. Research in Learning Technology, 28(2020), 1-23. https://10.25304/rlt.v28.2329

\section{Copyrights}

Copyright for this article is retained by the author(s), with first publication rights granted to the journal.

This is an open-access article distributed under the terms and conditions of the Creative Commons Attribution license (http://creativecommons.org/licenses/by/4.0/) 